\title{
Role of Molybdenum-Containing Enzymes in the Biotransformation of the Novel Ghrelin Receptor Inverse Agonist PF-5190457: A Reverse Translational Bed-to-Bench Approach ${ }^{\mathbb{్}}$
}

\author{
(D) Sravani Adusumalli, (1)Rohitash Jamwal, (1) R. Scott Obach, Tim F. Ryder, (DLorenzo Leggio, \\ and (1) Fatemeh Akhlaghi
}

Clinical Pharmacokinetics Research Laboratory, Department of Biomedical and Pharmaceutical Sciences, University of Rhode Island, Kingston, Rhode Island (S.A., R.J., F.A.); Department of Pharmacokinetics, Dynamics, and Metabolism, Pfizer, Inc., Groton, Connecticut (R.S.O., T.F.R.); Section on Clinical Psychoneuroendocrinology and Neuropsychopharmacology, National Institute on

Alcohol Abuse and Alcoholism Division of Intramural Clinical and Biological Research and National Institute on Drug Abuse

Intramural Research Program, Bethesda, Maryland (L.L.); Medication Development Program, National Institute on Drug Abuse Intramural Research Program, Baltimore, Maryland (L.L.); and Center for Alcohol and Addiction Studies, Department of Behavioral and Social Sciences, Brown University, Providence, Rhode Island (L.L.)

Received March 3, 2019; accepted May 28, 2019

\section{ABSTRACT}

(R)-2-(2-methylimidazo[2,1-b]thiazol-6-yl)-1-(2-(5-(6-methylpyrimidin4-yl)-2,3-dihydro-1H-inden-1-yl)-2,7-diazaspiro[3.5]nonan-7-yl)ethan1-one (PF-5190457) was identified as a potent and selective inverse agonist of the ghrelin receptor [growth hormone secretagogue receptor 1a (GHS-R1a)]. The present translational bed-to-bench work characterizes the biotransformation of this compound in vivo and then further explores in vitro metabolism in fractions of human liver and primary hepatocytes. Following oral administration of PF-5190457 in a phase 1b clinical study, hydroxyl metabolites of the compound were observed, including one that had not been observed in previously performed human liver microsomal incubations. PF-6870961 or (R)-1-(2-(5-(2-hydroxy-6-methylpyrimidin4-yl)-2,3-dihydro-1H-inden-1-yl)-2,7-diazaspiro[3.5]nonan-7-yl)-2(2-methylimidazo[2,1-b]thiazol-6-yl)ethan-1-one was biosynthesized using liver cytosol, and the site of hydroxylation was shown to be on the pyrimidine using nuclear magnetic resonance spectroscopy. The aldehyde oxidase (AO) inhibitor raloxifene and the xanthine oxidase inhibitor febuxostat inhibited the formation of PF-6870961 in human liver cytosol, suggesting both enzymes were involved in the metabolism of the drug. However, greater inhibition was observed with raloxifene, indicating $\mathrm{AO}$ is a dominant enzyme in the biotransformation. The intrinsic clearance of the drug in human liver cytosol was

This work was supported by the National Insititutes of Health National Center for Advancing Translational Sciences [Grant UH2/UH3-TR000963] (to L.L. and F.A.); intramural funding from the National Insititutes of Health Section on Clinical Psychoneuroendocrinology and Neuropsychopharmacology [Grant ZIA-AA000218] (to L.L.); jointly supported by the National Insititutes of Health Division of Intramural Clinical and Biological Research of the National Institute on Alcohol Abuse and Alcoholism and the Intramural Research Program of the National Institute on Drug Abuse.

R.S.O. and T.F.R. are active employees at Pfizer Inc., Groton, CT.

The content of this article is solely the responsibility of the authors and does not necessarily represent the official views of the National Insititutes of Health. Also, Pfizer provided the study drug for the phase $1 \mathrm{~b}$ clinical study but did not have any role in the study design, execution, or interpretation of the results, and this publication does not necessarily represent the official views of Pfizer. https://doi.org/10.1124/dmd.119.087015.

S This article has supplemental material available at dmd.aspetjournals.org. estimated to be $0.002 \mathrm{ml} / \mathrm{min}$ per milligram protein. This study provides important novel information at three levels: 1) it provides additional new information on the recently developed novel compound PF-5190457, the first GHS-R1a blocker that has moved to development in humans; 2) it provides an example of a reverse translational approach where a discovery in humans was brought back, validated, and further investigated at the bench level; and 3) it demonstrates the importance of considering the molybdenumcontaining oxidases during the development of new drug entities.

\section{SIGNIFICANCE STATEMENT}

PF-5190457 is a novel ghrelin receptor inverse agonist that is currently undergoing clinical development for treatment of alcohol use disorder. PF-6870961, a major hydroxyl metabolite of the compound, was observed in human plasma, but was absent in human liver microsomal incubations. PF-6870961 was biosynthesized using liver cytosol, and the site of hydroxylation on the pyrimidine ring was characterized. Inhibitors of aldehyde oxidase and xanthine oxidase inhibited the formation of PF-6870961 in human liver cytosol, suggesting both enzymes were involved in the metabolism of the drug. This information is important for patient selection in subsequent clinical studies.

\section{Introduction}

Ghrelin is a 28-amino acid peptide produced by endocrine cells primarily localized in the stomach. Ghrelin plays key roles in growth, appetite, food intake, glucose homeostasis, metabolism, and energy balance (Kojima et al., 1999; Asakawa et al., 2001; Inui et al., 2004; Nagaya et al., 2004, 2005; Neary et al., 2004; Tong et al., 2010). In its acylated form (traditionally referred to as active ghrelin), ghrelin binds to and activates the main ghrelin receptor, growth hormone secretagogue receptor $1 \mathrm{a}$, which is a $\mathrm{G}$ protein-coupled receptor with high intrinsic activity (Howard et al., 1996; Damian et al., 2012).

Recent research has focused on the overlap between obesity and addictions and how neurotransmitters and peptides regulating food intake can also influence craving for alcohol in alcohol-dependent individuals (Leggio et al., 2011; Volkow et al., 2013). Among others, 
the ghrelin system has been investigated in animal models and patients with alcohol dependence, and collectively these studies support a role for ghrelin in alcohol-seeking behaviors. Specifically, several rodent studies support the notion that the ghrelin system is causally involved in alcohol-seeking behaviors and these data have been further corroborated by human studies indicating an association between alcohol craving and drinking and the subjective effects of alcohol with the endogenous concentrations of peripheral ghrelin (Leggio, 2010; Zallar et al., 2017; Morris et al., 2018). Furthermore, two double-blind placebo-controlled human laboratory studies have shown that intravenous administration of ghrelin in alcohol-dependent heavy drinkers leads to increased cueinduced alcohol craving in a bar-like setting (Leggio et al., 2014) and increased alcohol self-administration and modulation of brain activity in areas involved in alcohol-seeking behaviors (Farokhnia et al., 2018). Together, rodent and human studies collectively suggest that blockade of growth hormone secretagogue receptor 1a may represent a potentially novel pharmacological approach to treat alcohol use disorder.

(R)-2-(2-methylimidazo[2,1-b]thiazol-6-yl)-1-(2-(5-(6-methylpyrimidin4-yl)-2,3-dihydro-1 $H$-inden-1-yl)-2,7-diazaspiro[3.5]nonan-7-yl)ethan1 -one (PF-5190457) is a member of a spiro-azetidino-piperidine series identified as a potent ghrelin receptor inverse agonist (Bhattacharya et al., 2014). PF-5190457 represents the first ghrelin receptor blocker that moved to clinical development and a recent phase $1 \mathrm{~b}$ drug-alcohol interaction placebo-controlled study showed the safety and tolerability of PF-5190457 when administered to heavy drinkers, including its coadministration with an oral alcohol challenge (Lee et al., 2018). As an additional safety outcome, this phase 1b study showed that PF-5190457 did not affect alcohol pharmacokinetics and it also showed indirectly that alcohol does not affect the pharmacokinetics of PF-5190457.

Limited information is available on the biotransformation of PF-5190457. The assessment of metabolic pathways of a new drug is important since it helps to understand the pharmacokinetics and pharmacodynamics of the compound in humans. It is also essential to identify the enzymes responsible for biotransformation, since this information contributes to an understanding of interindividual variability in pharmacokinetics that can be due to genetic polymorphism and/or drug-drug interactions. Additionally, metabolites generated by these enzymes could be pharmacologically active on the same receptor as the parent compound and/or have off-target effects (Lin and Lu, 1997; Kumar and Surapaneni, 2001; Fu et al., 2013).

The present study describes the biotransformation of PF-5190457 in vitro and the identification of PF-6870961 in humans. Specifically, the objectives of the present study were: 1) characterization of the circulating metabolites in vivo in human plasma, 2) determination of formation of metabolites in vitro in subcellular fractions of human liver and human hepatocytes, 3) determination of the structure of metabolites by mass spectrometry and NMR analyses, 4) assessment of the kinetic parameters of metabolite formation, and 5) identification of the enzyme(s) responsible for the formation of PF-6870961 using specific inhibitors for each enzyme.

\section{Materials and Methods}

PF-5190457, raloxifene hydrochloride, febuxostat, and tacrine were procured from Sigma Aldrich (St. Louis, MO). Allopurinol was purchased from Toronto Research Chemicals (Toronto, Canada). The major circulating hydroxy metabolite of PF-5190457 (also called PF-6870961) was biosynthesized as described subsequently. Recombinant aldehyde oxidase ( $\mathrm{rAOX}$ ) was produced by Dr. Ciaran Cronin (Pfizer, La Jolla, CA). NADPH tetrasodium salt was obtained from Calbiochem (EMD Millipore, Billerica, MA). Liquid chromatography (LC) mass spectrometry (MS) grade methanol, acetonitrile, and formic acid were obtained from Fisher Scientific (Fairlawn, NJ). All other reagents and chemicals used in the study were of analytical grade and were used without further purification.

\section{In Vivo Metabolite Profiling}

Sample Preparation. Plasma samples from a recent phase $1 \mathrm{~b}$ study were analyzed by high-resolution MS to identify the circulating metabolites (Lee et al., 2018). Plasma samples from twice daily $100 \mathrm{mg}$ doses (patients N101, N102, and N103) were pooled and prepared for metabolite profiling experiments at various sampling times [predose, early (30 and 60 minutes), and late (1350 and 1440 minutes)]. Plasma proteins were precipitated with the addition of acetonitrile $(5 \mathrm{ml})$ followed by vortex mixing and centrifugation at $1700 \mathrm{~g}$ for 5 minutes. The supernatant was transferred and evaporated for 4 hours in a vacuum centrifuge (Genevac; SP Scientific, Gardiner, NY), and subsequently reconstituted in $30 \mu \mathrm{l}$ acetonitrile followed by addition of $120 \mu \mathrm{l}$ water. The reconstituted samples were spun for 3 minutes to remove particulates, and $10 \mu \mathrm{l}$ of an aliquot of the reconstituted solution was injected onto an ultrahigh-performance LC/high-resolution MS system.

High-Resolution Mass Spectrometry. Chromatographic separation for metabolite profiling was achieved using a Waters HSS-T3 C18 column $(1.8 \mu \mathrm{m} ; 2.1 \times$ $100 \mathrm{~mm}$; Waters Corp., Milford, MA) maintained at $45^{\circ} \mathrm{C}$ in line with a Thermo Accela high-performance LC (HPLC) pump, CTC Analytics autoinjector, a photodiode array detector, and a Thermo Orbitrap Elite ion trap high-resolution mass spectrometer (Thermo Fisher Scientific Inc., Waltham, MA). The mobile phase consisted of $10 \mathrm{mM}$ ammonium acetate (A) and acetonitrile (B), and separation was achieved at a flow rate of $0.35 \mathrm{ml} / \mathrm{min}$. The gradient elution was started from $5 \% \mathrm{~B}$, maintained for 0.5 minutes, increased to $50 \% \mathrm{~B}$ over 10 minutes, increased to $95 \% \mathrm{~B}$ over the next 2 minutes, and finally decreased to $5 \%$ B to reequilibrate the column with a total run time of 15 minutes. The MS detector was operated in positive ion electrospray mode.

\section{In Vitro Biotransformation of PF-5190457}

Preparation of Subcellular Fractions. Human liver tissues and human hepatocytes were obtained from Xenotech (Lenexa, KS). The hepatocytes, liver microsomes, or cytosols were pooled from donors of both sexes. Human liver microsome (HLM) and human liver cytosol (HLC) fractions were prepared by differential ultracentrifugation from the human liver as described previously (Jamwal et al., 2017). Total protein concentrations for the HLM and HLC were determined using the Pierce BCA Protein Assay Kit (Thermo Fisher Scientific Inc.) and the fractions were stored at $-80^{\circ} \mathrm{C}$ until further analysis.

HLM and HLC Incubations. The in vitro metabolism of PF-5190457 was studied using HLM and HLC fractions. PF-5190457 was incubated (50-100 $\mu \mathrm{M})$ with pooled HLM and HLC in $100 \mathrm{mM}$ potassium phosphate buffer ( $\mathrm{pH} 7.4)$, in which the methanol concentration from substrate addition was kept below $0.5 \%$. Incubations were conducted at $37^{\circ} \mathrm{C}$ in a water bath, where the total incubation mixture volume was $50 \mu \mathrm{l}$. The total protein concentration used for both HLM and HLC ranged from 0.05 to $2 \mathrm{mg} / \mathrm{ml}$. PF-5190457 was also incubated in only $100 \mathrm{mM}$ potassium phosphate buffer ( $\mathrm{pH}$ 7.4) without HLM or HLC as a control. Microsomal incubations were conducted with and without the addition of NADPH. Reactions in HLM and HLC were initiated by the addition of substrate. The reaction was terminated by the addition of $200 \mu \mathrm{l}$ of ice-cold methanol at various incubation times (0-120 minutes). Subsequently, the samples were centrifuged for 5 minutes at 10,000 rpm to remove the precipitated protein, and were ten analyzed as described subsequently.

Liquid Chromatography-Tandem Mass Spectrometry Analysis of HLM and HLC Samples. Samples were analyzed using an Acquity UPLC System coupled to a Xevo-TQ mass spectrometer (Waters Corp). Analytes were chromatographically separated on a C18 column (Acquity UPLC BEH $2.1 \times 50 \mathrm{~mm}$ )

ABBREVIATIONS: AO, aldehyde oxidase; 2D, two-dimensional; HLC, human liver cytosol; HLM, human liver microsome; HPLC, high-performance liquid chromatography; HSQC, heteronuclear single quantum coherence; IS, internal standard; LC, liquid chromatography; MS, mass spectrometry; $\mathrm{m} / \mathrm{z}$, mass-to-charge ratio; PF-5190457, (R)-2-(2-methylimidazo[2,1-b]thiazol-6-yl)-1-(2-(5-(6-methylpyrimidin-4-yl)-2,3-dihydro-1H-inden-1-yl)-2,7diazaspiro[3.5]nonan-7-yl)ethan-1-one; PF-6870961 (R)-1-(2-(5-(2-hydroxy-6-methylpyrimidin-4-yl)-2,3-dihydro-1H-inden-1-yl)-2,7-diazaspiro[3.5] nonan-7-yl)-2-(2-methylimidazo[2,1-b]thiazol-6-yl)ethan-1-one; rAOX, recombinant aldehyde oxidase; RT, retention time; XO, xanthine oxidase. 
with $1.7 \mu \mathrm{m}$ particle size and $130 \AA$ A porosity. A precolumn (Acquity UPLC BEH C18, $2.1 \times 5 \mathrm{~mm}$ ) was connected prior to the analytical column. The mobile phase consisted of water:methanol $(95: 5, \mathrm{v} / \mathrm{v})$ containing $0.1 \%$ formic acid (A) and $100 \%$ methanol containing $0.1 \%$ formic acid (B). The column and autosampler temperatures were kept at 40 and $10^{\circ} \mathrm{C}$, respectively. The mobile phase was delivered at a flow rate of $0.25 \mathrm{ml} / \mathrm{min}$, in which the injection volume was $5 \mu \mathrm{l}$. The total assay run time was 12 minutes and 30 seconds. Mobile phase A was maintained at $98 \%$ for the initial 2 minutes, decreased to $50 \%$ at 8 minutes and 30 seconds, decreased to $5 \%$ over the next 2 minutes, and then returned to the initial conditions for equilibration at 10 minutes and 30 seconds. A full scan from 100 to $1200 \mathrm{Da}$ was carried out in positive electrospray ionization mode with the following parameters: desolvation temperature, $-600^{\circ} \mathrm{C}$; desolvation gas flow, $-1000 \mathrm{l} / \mathrm{h}$; capillary voltage, $-3.50 \mathrm{kV}$; and cone voltage, $-30 \mathrm{~V}$. Similarly, single-ion monitoring for the $[\mathrm{M}+\mathrm{H}]^{+}$ions of PF-5190457 [mass-tocharge ratio $(\mathrm{m} / \mathrm{z}) 513.2]$ and the anticipated metabolites, i.e., hydroxy metabolite $(\mathrm{m} / \mathrm{z} 513.2+16)$, glucuronide $(\mathrm{m} / \mathrm{z}, 513.2+176)$, and hydroxy glucuronide $(\mathrm{m} / \mathrm{z} 513.2+192)$ was performed (Table 1$)$.

Hepatocyte Incubations. PF-05190457 was incubated in pooled cryopreserved human hepatocytes $(750,000$ cells $/ \mathrm{ml}$; In Vitro Technologies, Baltimore, $\mathrm{MD}$ ) with and without 1-aminobenzotriazole (a pan CYP450 inhibitor) at $1 \mathrm{mM}$, or hydralazine [a selective probe inactivator of aldehyde oxidase (AO)] at 0.05 mM (Ortiz de Montellano and Mathews, 1981; Strelevitz et al., 2012). Incubations were carried out on a rotating shaker placed in an incubator maintained under an atmosphere of $\mathrm{O}_{2} / \mathrm{CO}_{2}(95: 5)$ and relative humidity of $75 \%$. Incubations were carried out for 4 hours and then were stopped by snap freezing in a dry ice/acetone bath. The samples were prepared and analyzed as described previously for HLM and HLC incubations.

\section{Biosynthesis and NMR Analysis}

Biosynthesis of PF-6870961, the Major Hydroxy Metabolite of PF-5190457. PF-5190457 $(20 \mu \mathrm{M})$ was incubated with female mouse liver cytosol $(2.0 \mathrm{mg} / \mathrm{ml}$; Corning-Gentest, Woburn, MA) in $40 \mathrm{ml}$ potassium phosphate buffer $(100 \mathrm{mM}$, $\mathrm{pH} 7.5$ ) in a shaking water bath maintained at $37^{\circ} \mathrm{C}$ for 1.5 hours. The incubation was terminated with the addition of $\mathrm{CH}_{3} \mathrm{CN}(40 \mathrm{ml})$, and the precipitated material was removed by spinning in a centrifuge for 5 minutes at $1700 \mathrm{~g}$. The supernatant was partially evaporated in a Genevac vacuum centrifuge for 2 hours. Then, $0.25 \mathrm{ml}$ neat formic acid, $0.25 \mathrm{ml} \mathrm{CH}{ }_{3} \mathrm{CN}$, and water were added to the remaing mixture for a final volume of $25 \mathrm{ml}$. This mixture was spun in a centrifuge at $40,000 \mathrm{~g}$ for 30 minutes and the clarified supernatant was applied to an HPLC column (Polaris C18; $4.6 \times 250 \mathrm{~mm} ; 5 \mu \mathrm{m}$ ) through a Jasco HPLC pump at a rate of $0.8 \mathrm{ml} / \mathrm{min}$. After the entire sample was applied, an additional $\sim 5 \mathrm{ml}$ of mobile phase $\left(0.1 \%\right.$ formic acid containing $\left.1 \% \mathrm{CH}_{3} \mathrm{CN}\right)$ was pumped through the system. The column was moved to a Thermo LTQ HPLC-MS system containing a photodiode array detector, and a mobile phase gradient was applied to elute the material of interest. The mobile phase was comprised of $0.1 \%$ formic acid in water (A) and $\mathrm{CH}_{3} \mathrm{CN}(\mathrm{B})$ and was run at a flow rate of $0.8 \mathrm{ml} / \mathrm{min}$. The gradient began at a composition of $2 \% \mathrm{~B}$ for 5 minutes followed by a linear gradient to $25 \% \mathrm{~B}$ for 70 minutes. The eluent passed through the photodiode array detector scanning from 200 to $400 \mathrm{~nm}$ and then to a splitter (the ratio was approximately 15:1) with the larger portion going to a CTC Leaptec fraction collector (CTC, Cary, NC). Fractions were collected every 20 seconds. The remainder was introduced into the mass spectrometer operating in the positive ion mode. The fractions proposed to contain the hydroxy metabolites of interest were analyzed for identity and purity on a Thermo Orbitrap Elite ultra-high-performance LC/UV/ MS system containing an Acquity column (HSS T3 C18; $2.1 \times 100 \mathrm{~mm}, 1.7 \mu \mathrm{m}$ particle size) using the method described previously at a flow rate of $0.4 \mathrm{ml} / \mathrm{min}$ and an injection volume of $5 \mu$ l. Fractions containing single peaks by UV and the desired protonated molecular ions were combined and evaporated by vacuum centrifugation for analysis by NMR spectroscopy. The samples were reconstituted with $100 \mu \mathrm{l}$ of DMSO-d6 100\% (Cambridge Isotope Laboratories, Andover, MA) before NMR analysis and ${ }^{1} \mathrm{H}$ NMR and two-dimensional (2D) NMR $\left[{ }^{1} \mathrm{H}\right.$ correlation spectroscopy, heteronuclear multiple bond correlation, and heteronuclear single quantum coherence (HSQC)] analyses were carried out as described subsequently.

\section{NMR Sample Analysis}

Isolated samples were reconstituted in $0.10 \mathrm{ml}$ of DMSO-d6 $100 \%$ and placed in a $1.7 \mathrm{~mm}$ NMR tube that had been stored in dry argon atmosphere. The ${ }^{1} \mathrm{H}$ and ${ }^{13} \mathrm{C}$ spectra were referenced using residual DMSO-d6 $\left({ }^{1} \mathrm{H} \delta=2.50 \mathrm{ppm}\right.$ relative to tetramethylsilane (TMS), $\delta=0.00 ;{ }^{13} \mathrm{C} \delta=39.50 \mathrm{ppm}$ relative to TMS, $\delta=$ 0.00). NMR spectra were recorded on a Bruker Avance $600 \mathrm{MHz}$ (Bruker BioSpin Corporation, Billerica, MA) controlled by Topspin version 3.2 and equipped with a $1.7 \mathrm{~mm}$ TCI Cryo probe. One-dimensional spectra were recorded using an approximate sweep width of $8400 \mathrm{~Hz}$, and a total recycle time of approximately 7 seconds. The resulting time-averaged free-induction decays were transformed using an exponential line broadening of $1.0 \mathrm{~Hz}$ to enhance the signal to noise. The 2D data were recorded using the standard pulse sequences provided by Bruker. At a minimum, a $1 \mathrm{~K} \times 128$ data matrix was acquired using a minimum of two scans and 16 dummy scans with a spectral width of $10,000 \mathrm{~Hz}$ in the $\mathrm{f} 2$ dimension. The 2D data sets were zero filled to at least $1 \mathrm{~K}$ data points. Postacquisition data processing was performed with Topspin version 3.2 MestReNova. Quantitation of NMR isolates was performed by external calibration against the ${ }^{1} \mathrm{H}$ NMR spectrum of $5 \mathrm{mM}$ benzoic acid standard compared with that of the isolated metabolites using the ERETIC2 function within Topspin version 3.2.

\section{Enzyme Kinetic Studies}

The formation of the PF-6870961 in rAOX and HLC fractions was studied to determine the enzyme kinetic parameters. Before the assessment of the enzyme kinetics, the protein concentration and incubation time linearity of PF-6870961 formation were evaluated to choose the optimum conditions.

rAOX Incubations. PF-5190457 $(0.5-125 \mu \mathrm{M})$ was incubated with rAOX $(0.090 \mathrm{mg} / \mathrm{ml})$ in $100 \mathrm{mM}$ potassium phosphate buffer. The incubations were conducted at $37^{\circ} \mathrm{C}$ in a shaking water bath. The incubation mixture volume was $50 \mu \mathrm{l}$, and all incubations were performed in triplicate. The reactions were terminated after 120 minutes using methanol containing $2.5 \mathrm{ng} / \mathrm{ml}$ tacrine [internal standard (IS)]. Samples were processed and analyzed as described subsequently.

HLC Incubations. The kinetic parameters for the formation of PF-6870961 from PF-5190457 were determined by incubating the drug in pooled, allopurinol/ oxypurinol-free, HLC (Supplemental Material). The optimized total protein concentration and incubation time in HLC were $0.1 \mathrm{mg} / \mathrm{ml}$ and 5 minutes, respectively. PF-5190457 $(0.05-100 \mu \mathrm{M})$ with HLC in a total volume of $50 \mu \mathrm{l}$ of $100 \mathrm{mM}$ potassium phosphate buffer $(\mathrm{pH} 7.4)$ were incubated at $37^{\circ} \mathrm{C}$ in duplicate. The final concentration of methanol in the incubations was $<0.25 \%$. The reaction was initiated by the addition of cytosol and terminated by protein precipitation with the addition of methanol $(200 \mu \mathrm{l})$ containing the $2.5 \mathrm{ng} / \mathrm{ml}$ tacrine as IS.

Liquid Chromatography-Tandem Mass Spectrometry Analysis for Kinetic Studies. All samples from rAOX and HLC incubations were centrifuged for 5 minutes at $10,000 \mathrm{rpm}$. The supernatants were removed and analyzed as

TABLE 1

Mass spectrometry parameters of analytes and internal standard

\begin{tabular}{|c|c|c|c|c|c|c|}
\hline \multirow{2}{*}{ Compound } & \multicolumn{2}{|c|}{$\mathrm{m} / \mathrm{z}$} & \multirow{2}{*}{ Dwell } & \multirow{2}{*}{ Cone } & \multirow{2}{*}{ Collision Energy } & \multirow{2}{*}{ Retention Time } \\
\hline & Precursor & Product & & & & \\
\hline & & & $s$ & V & V & $\min$ \\
\hline Parent drug (PF-5190457) & 513 & 209,335 & 0.025 & 30,30 & 44,16 & 5.6 \\
\hline Major hydroxyl metabolite (PF-6870961) & 529 & 225,351 & 0.025 & 34,32 & 40,20 & 4.5 \\
\hline Internal standard (Tacrine) & 199 & 170,143 & 0.025 & 46,42 & 30,36 & 5.9 \\
\hline
\end{tabular}


follows. The parent, metabolite, and IS were monitored using Xevo TQ-MS (Waters Corp.) coupled to an Acquity UPLC System (Waters Corp.). The analytes were separated using an Aquity UPLC BEH C18 $(2.1 \times 50 \mathrm{~mm}$, $1.7 \mu \mathrm{m}$ particle size, $130 \AA$ pore size) analytical column with an Acquity UPLC BEH C18 VanGuard precolumn $(2.1 \times 5 \mathrm{~mm}, 130 \AA \hat{)})$. Mobile phase solution A consisted of water:methanol $95 \% / 5 \%(\mathrm{v} / \mathrm{v})$ and mobile phase solution B consisted of methanol (100\%). Formic acid $(0.1 \%)$ was added to both mobile phase solutions. The flow rate was $0.25 \mathrm{ml} / \mathrm{min}$ with a run time of 10 minutes and 30 seconds. The column temperature was maintained at $40^{\circ} \mathrm{C}$. The gradient consisted of $2 \%$ methanol for 2 minutes, increased to $35 \%$ for 2 minutes to 7 minutes and 30 seconds, further increased to 95\% methanol at 8 minutes, and held until 8 minutes and 30 seconds before returning to the initial conditions to equilibrate with a total run time of 10 minutes and 30 seconds. Mass spectral analysis and quantification were carried out using Multiple Reaction Monitoring (MRM) in positive electrospray ionization mode with the following parameters: desolvation temperature of $350^{\circ} \mathrm{C}$, desolvation gas flow of $650 \mathrm{l} / \mathrm{h}$, capillary voltage of $3.50 \mathrm{kV}$ and cone voltage of $20 \mathrm{~V}$. The optimized settings of the mass spectrometer voltage and the retention time (RT) for the analytes and IS with quantifier and qualifier fragments are summarized in Supplemental Table 1. Data acquisition and processing were performed using MassLynx (version 4.1) and TargetLynx, respectively. The retention times for PF-6870961 and the internal standards were 4.4 and 5.1 minutes, respectively. Quantitation was done using the PF-6870961 standard curve ranging from 0.1 to $1 \mu \mathrm{M}$. The calibration standards were within $\pm 15 \%$ of nominal values.

\section{Inhibition Studies}

Incubation of PF-5190457 in HLC (with AO and Xanthine Oxidase Inhibitors). PF-5190457 $(25 \mu \mathrm{M})$ was incubated with pooled allopurinol/ oxypurinol-free HLC $(0.1 \mathrm{mg} / \mathrm{ml}, n=9)$ in a total volume of $50 \mu \mathrm{l}$ of $100 \mathrm{mM}$ potassium phosphate buffer ( $\mathrm{pH}$ 7.4) in the presence and absence of inhibitors. Incubation conditions were similar to previous HLC kinetic experiments. To identify the enzymes involved in the formation of PF-6870961, HLC was incubated with and without AO inhibitor (raloxifene 0.005-50 $\mu \mathrm{M}$ ), and xanthine oxidase (XO) inhibitor (febuxostat $0.001-50 \mu \mathrm{M}$ ). The reactions were terminated at 5 minutes using methanol containing $2.5 \mathrm{ng} / \mathrm{ml}$ tacrine (IS). The samples were analyzed using LC-tandem MS as described under enzyme kinetic studies.

\section{Data Analysis}

Estimations of the maximum rate of PF-6870961 formation $\left(V_{\max }\right)$ and the Michaelis-Menten constant $\left(K_{\mathrm{m}}\right)$ were performed using nonlinear regression analysis within Prism 6 (GraphPad Software Inc., La Jolla, CA) using the Michaelis-Menten equation $\left[V=\left(V_{\max } \times S\right) /\left(K_{\mathrm{m}}+S\right)\right]$. The apparent in vitro intrinsic clearance was calculated as $V_{\max } / K_{\mathrm{m}}$.

\section{Results}

\section{Characterization of PF-5190457 Metabolites in Human Plasma}

The circulating metabolites of PF-5190457 were determined in the plasma of human subjects who were administered PF-5190457 orally in the phase $1 \mathrm{~b}$ clinical study (Lee et al., 2018) (Fig. 1). Two peaks with protonated molecular ions of 16 mass units greater than PF-5190457 were observed $(\mathrm{m} / \mathrm{z}$ 529.2382), indicating the addition of oxygen. Fragment ions of PF-6870961 that had greater ion abundance included $\mathrm{m} / \mathrm{z}, 351.2179,305.1430$, and 225.1022 are indicative of oxidative biotransformation on the indenyl-pyrimidine portion of the parent molecule. Additional metabolites proposed as glucuronide and hydroxy glucuronide conjugates $(\mathrm{m} / \mathrm{z}, 689$ and 705) were detected at apparent lower levels in the plasma. A small signal peak in the mass spectrometer was observed, indicating the addition of water $(\mathrm{m} / \mathrm{z}, 531)$, but no further information was obtained.

\section{In Vitro Biotransformation of PF-5190457}

HLM and HLC Incubations. Experiments conducted in the subcellular fractions of human liver generated the PF-6870961 in HLC without the addition of cofactors (Fig. 2A). This metabolite was not observed in HLM supplemented with NADPH. PF-6870961 was detected in HLC as the protonated molecular ion $[\mathrm{M}+\mathrm{H}]^{+}$at $\mathrm{m} / \mathrm{z}$ 529 and produced fragments at $m / z, 225$ and 351 (Fig. 2B). The metabolite formed in HLC increased with the incubation time, concentration of substrate, and concentration of cytosol.

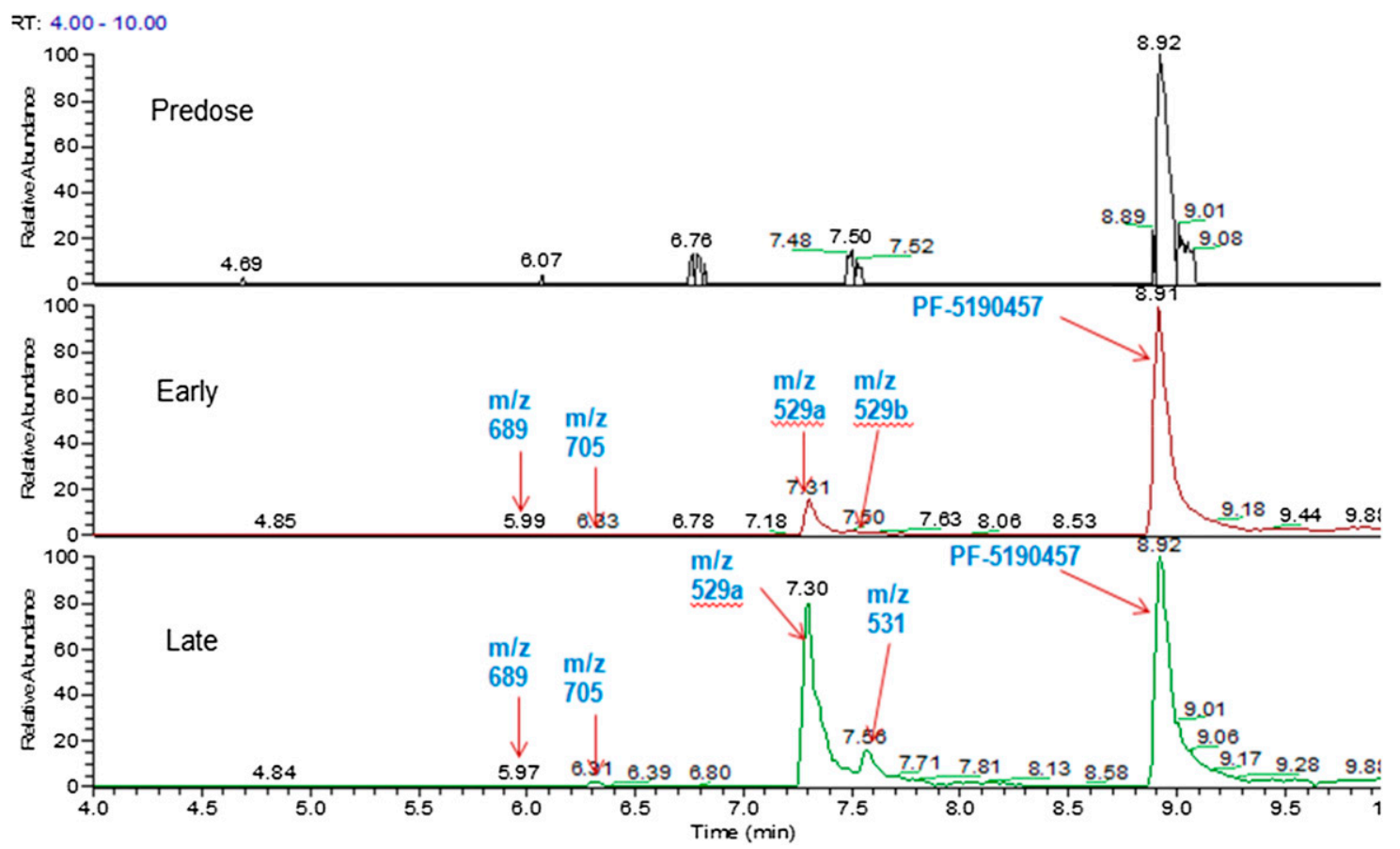

Fig. 1. Metabolic profiles of pooled patient plasma samples at various sampling times [predose, early ( 30 and 60 minutes), and late (1350 and 1440 minutes)] after administration of $100 \mathrm{mg}$ PF-5190457 analyzed by HPLC)/UV and HPLC-tandem MS (representative $\mathrm{m} / \mathrm{z}$ of the detected metabolites). 
A
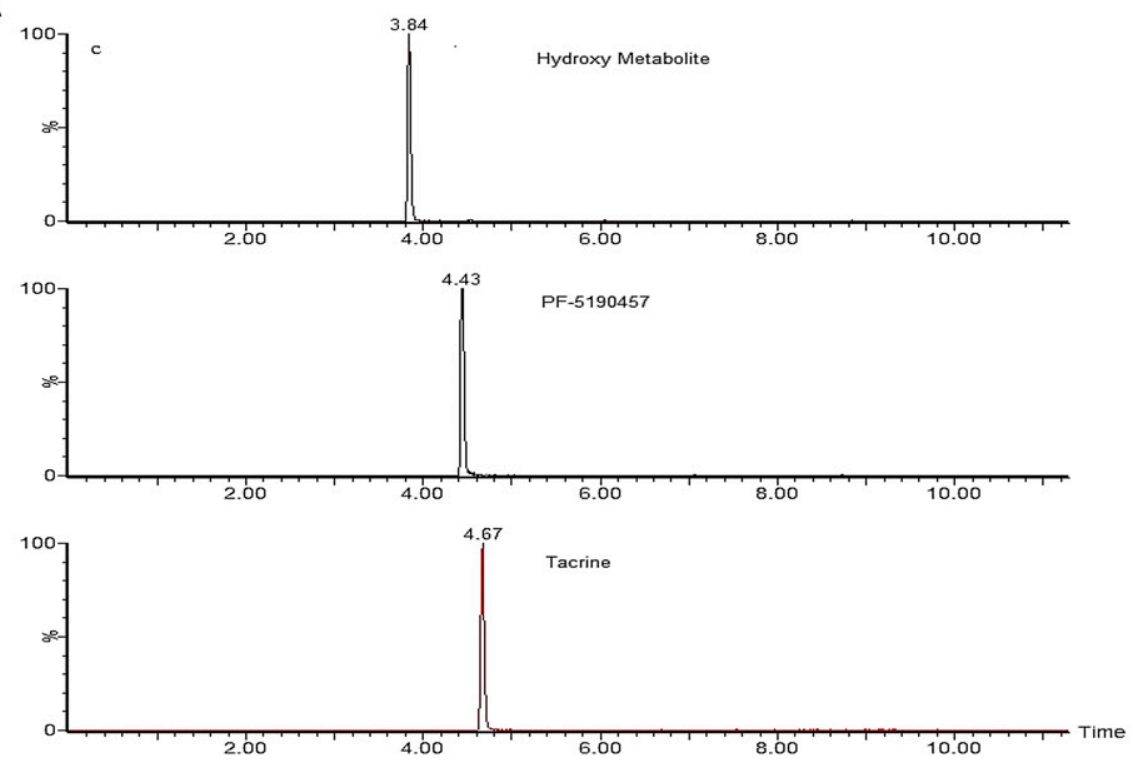

B

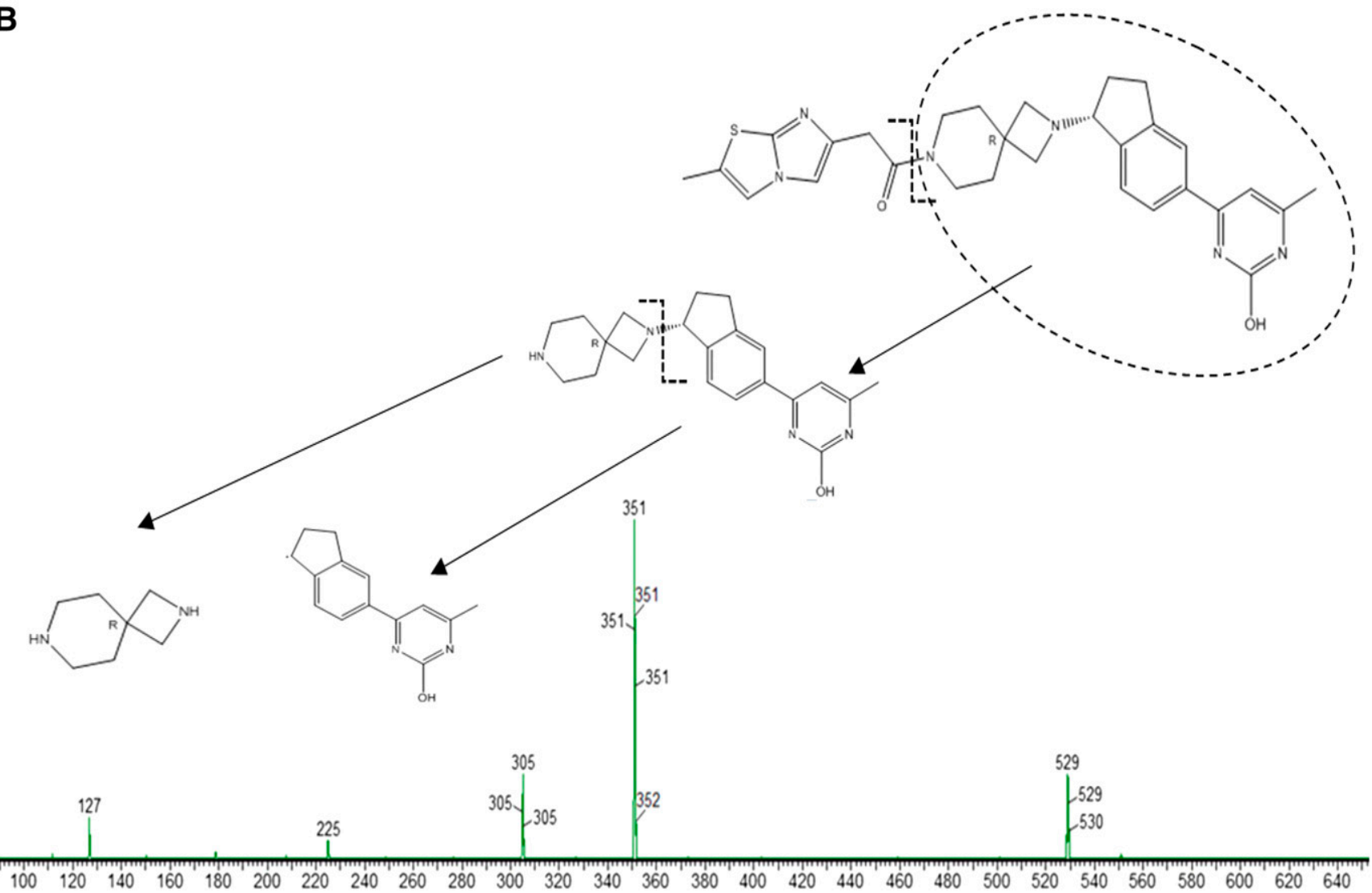

Fig. 2. (A) Representative chromatogram of PF-6870961, the major hydroxy metabolite formation in HLC. (B) Full scan and product ion scan of PF-6870961, the major metabolite (529a), detected at 7 minutes and 30 seconds in the pooled human plasma samples.

Hepatocyte Incubations. The formation of PF-6870961 was observed in human hepatocytes as shown in the chromatogram (Fig. 3). The traces are extracted ion chromatograms of $\mathrm{m} / \mathrm{z} 529.2376$ (5 ppm tolerance) representing the protonated molecular ion of a hydroxylated metabolite. The addition of 1-aminobenzotriazole, a broad-spectrum cytochrome P450 inactivator, inhibited the formation of the apparent minor metabolites at $\mathrm{RT}=4.12,4.62$, and 5.57 minutes and did not affect the metabolite eluting at RT $=3.98$ minutes, suggesting that cytochrome P45 mediated metabolism for the minor metabolites and not the major circulating metabolite, PF-6870961. It was also observed that the addition of hydralazine inhibited the formation of the metabolite at $\mathrm{RT}=3.97$ minutes, indicating that $\mathrm{AO}$ could be the primary enzyme involved in the biotransformation of PF-5190457 in human liver (Supplemental Fig. 1). 


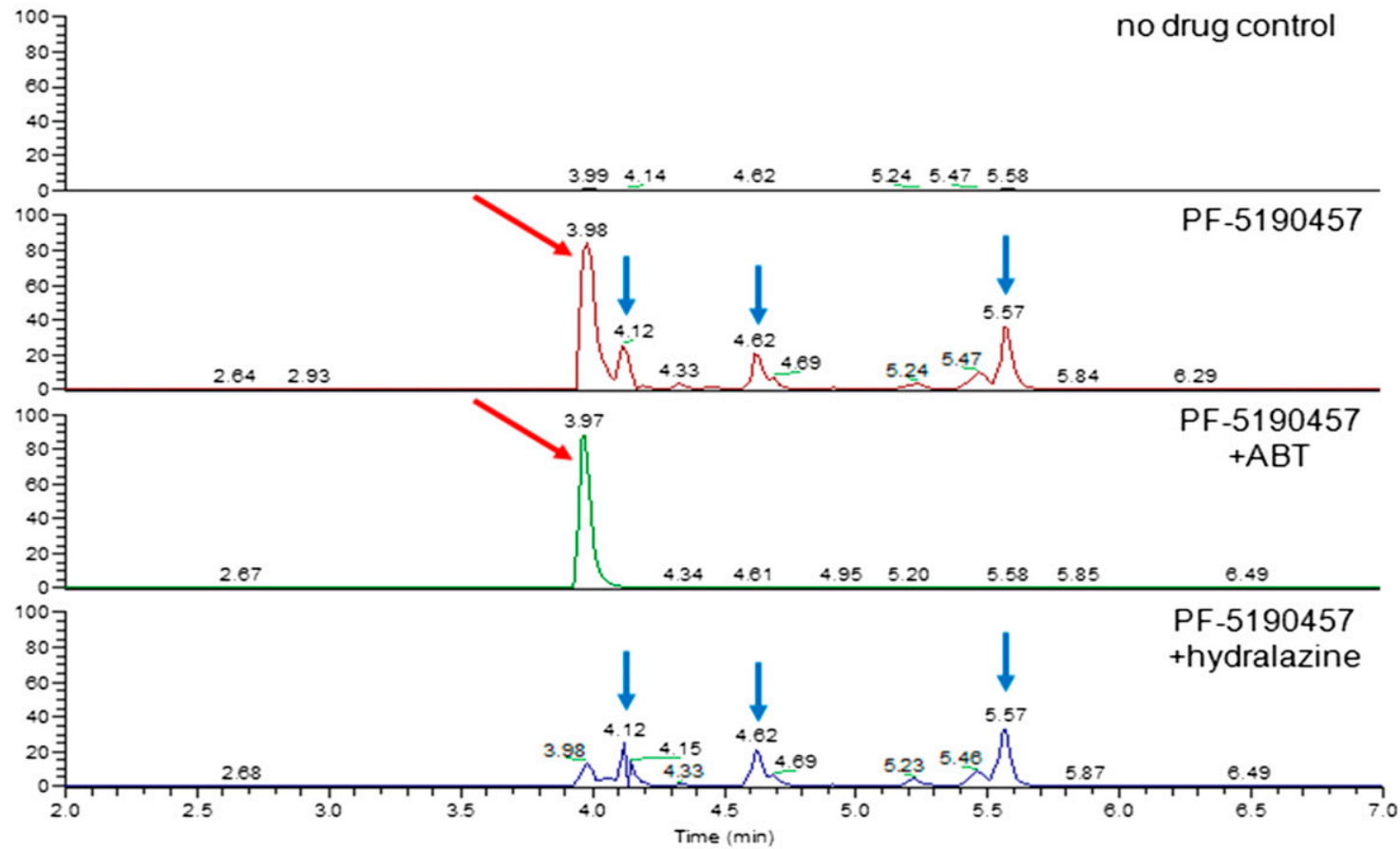

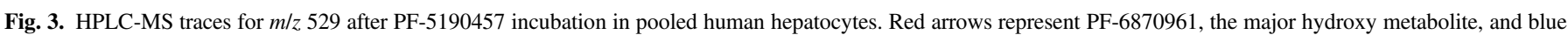
arrows represent other metabolites.

\section{Identification of Metabolite by NMR Spectroscopy}

${ }^{1} \mathrm{H}$ NMR and 2D NMR analyses of the parent compound PF-05190457 were performed for comparison against the spectra of the isolated metabolite. (Full interpretation and spectra are included in Supplemental Figs. 2-10). Comparison of the parent and metabolite ${ }^{1} \mathrm{H}$ spectrum showed one less aromatic proton with significant chemical shifts occurring on the 4-methylpyrimidine moiety (Fig. 4). The methylene group on the 4-methylpyrimidine moiety was observed intact with an upfield chemical shift from $\delta 2.51$ to $\delta 2.27$. The HSQC spectrum of the parent compound demonstrated the protons of the methyl group of the 4-methylpyrimidine moiety at $\delta 2.51$ were long ranged coupled into a carbon having a chemical shift of $\delta 115.8$, which was determined to have an attached proton at $\delta 7.95$ from the HSQC spectrum. Similarly, the heteronuclear multiple bond correlation spectrum of the metabolite demonstrated the protons of the methyl group of the 4-methylpyrimidine moiety at $\delta 2.27$ were long ranged coupled into a carbon having a new

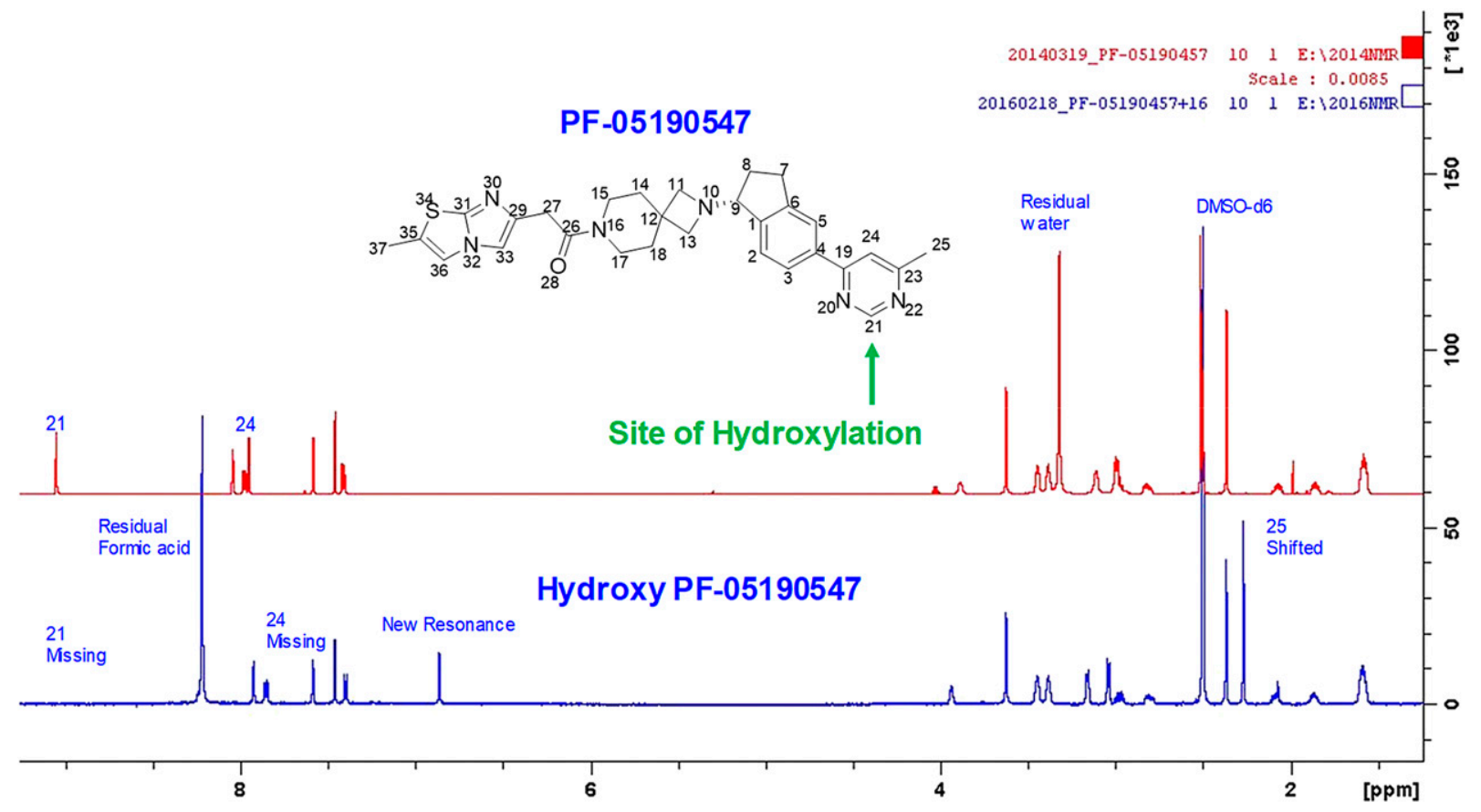

Fig. 4. ${ }^{1} \mathrm{H}$ NMR spectra of PF-05190547 (top) and isolatedPF-05190547 M+16 metabolite (bottom). 
chemical shift of $\delta$ 99.7, which was determined to have an attached proton at $\delta 6.86$ from the HSQC spectrum. This suggests the proton ortho to the methyl group on the 4-methylpyrimidine moiety observed in the parent compound is still intact in the metabolite but shifted from $\delta 7.95$ to $\delta 6.86$. Also noted in the ${ }^{1} \mathrm{H}$ spectrum of the metabolite was the absence of the aromatic proton resonance at $\delta 9.05$ observed in the parent compound, which was determined to be the proton meta to the methyl group on the 4-methylpyrimidine moiety between the two nitrogens. This suggests the site of oxidation is on the carbon between the two nitrogens of the 4-methylpyrimidine moiety.

\section{Enzyme Kinetic Analysis}

Representative Michaelis-Menten kinetic plots of PF-6870961 formation in rAOX and HLC are depicted in Figs. 5 and 6, respectively. Substrate inhibition kinetics at higher concentrations of substrate was observed in rAOX incubations. The $K_{\mathrm{m}}$ and $V_{\max }$ values for the formation of PF-6870961 in rAOX and HLC were found to be $6.9 \pm 0.8 \mu \mathrm{M}$ and $357.9 \pm 19.2 \mathrm{pmol} / \mathrm{min}$ per milligram protein, and $42.8 \pm 4.1 \mu \mathrm{M}$ and $119.6 \pm 3.6 \mathrm{pmol} / \mathrm{min}$ per milligram protein, respectively. The intrinsic clearances in $\mathrm{rAOX}$ and HLC were 0.06 and $0.002 \mathrm{ml} / \mathrm{min}$ per milligram protein, respectively. The differences in $K_{\mathrm{m}}$ values between HLC and rAOX are acknowledged but remain unexplained.

\section{Biotransformation of PF-5190457 Is Mediated by AO and XO}

The effect of AO (raloxifene) and XO (febuxostat) inhibitors on the metabolism of PF-5190457 in HLC was investigated. There was considerable $(>75 \%)$ but not complete inhibition of the formation of PF-6870961 with $50 \mu \mathrm{M}$ raloxifene (Fig. 7). The extent of inhibition with febuxostat was greater than $50 \%$ at $1 \mu \mathrm{M}$ (Fig. 7), and a further increase in the inhibitor concentration did not reduce the formation of the metabolite. Thus, the maximum inhibition value in HLC is indicative of the maximum contribution of the affected enzyme. It can be concluded that both $\mathrm{AO}$ and $\mathrm{XO}$ contribute, and the inhibition values suggest that the contributions of each are of similar magnitude.

\section{Discussion}

Currently, alcohol use disorder is the only potential target under study, at least clinically, for PF-5190457. Furthermore, Denney et al. (2017) suggested other indications (central nervous system indications such as sleep problems, shift work disorder, and Prader-Willi) rather than metabolic indications such as diabetes (given the tachyphylaxis they

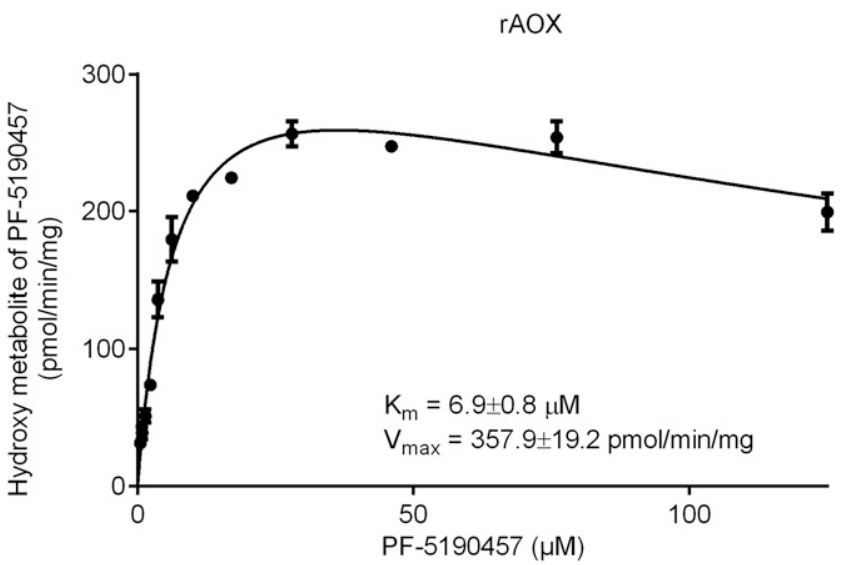

Fig. 5. Representative kinetics for the metabolism of PF-5190457 to hydroxy metabolite PF-6870961, in rAOX incubations.
Human Liver Cytosol

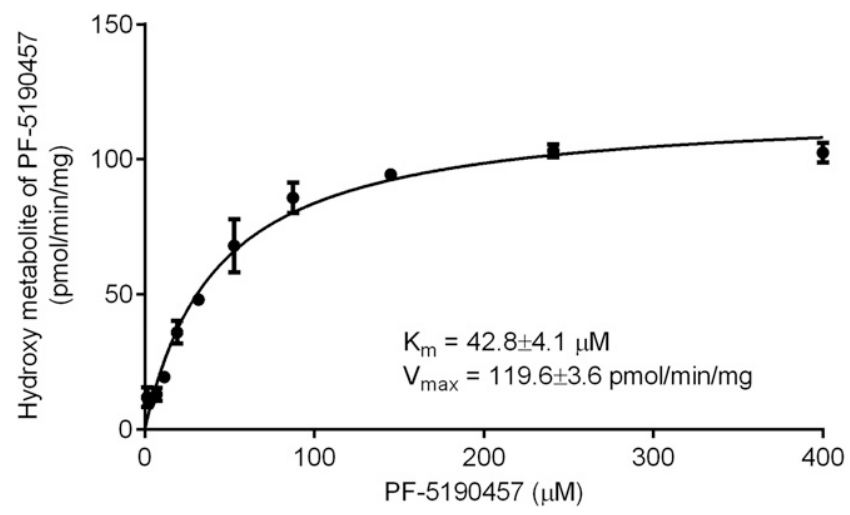

Fig. 6. Representative kinetics for the metabolism of PF-5190457 to a hydroxy metabolite PF-6870961 in HLC incubations.

saw after 14-day administration). The characterization of circulating metabolites from patients orally administered with the ghrelin receptor inverse agonist PF-5190457 revealed the biotransformation pathways for this novel compound. The primary route of metabolism observed in humans was hydroxylation, yielding PF-6870961. In vitro experiments showed that this metabolite was generated in human liver cytosol. The metabolite observed as PF-6870961 ( $\mathrm{m} / \mathrm{z}$ 529a) in human plasma and the metabolite formed in HLC $(\mathrm{m} / \mathrm{z}, 529)$ showed a similar tandem MS fragmentation pattern $(\mathrm{m} / \mathrm{z} 225$ and $\mathrm{m} / \mathrm{z}, 351)$, suggesting hydroxylation on the pyrimidine ring and yielding a strong correlation between in vivo and in vitro data. As such, this work also represents a practical example of a bed-to-bench approach, where a discovery from humans is then confirmed in vitro and leads to additional bench work as that described here in this translational work.

Hydroxylation reactions of drugs are almost always catalyzed by cytochrome P450 enzymes; however, in some instances hydroxylation of drugs containing aromatic azaheterocyclic moieties (e.g., pyrimidines and others) can be catalyzed by AO or XO. Results from experiments herein suggest that the primary biotransformation of PF-5190457 is via an NADPH-independent reaction in HLC leading to the formation of a hydroxypyrimidine metabolite. The position of hydroxylation on the pyrimidine ring between the two nitrogen atoms suggests nucleophilic attack via AO and/or XO enzymes in the metabolism of the drug (Krenitsky et al., 1972; Beedham, 1985; Kitamura et al., 2006). In contrast to electrophilic oxidation by CYP450 enzymes, both AO and $\mathrm{XO}$ enzymes catalyze their reactions by a mechanism of nucleophilic attack on carbon atoms that are electron deficient, such as those adjacent to nitrogen on aromatic N-heterocycle resulting in the formation of distinct metabolites (Krenitsky et al., 1972). Furthermore, the use of inhibitors indicated the contribution of both $\mathrm{AO}$ and $\mathrm{XO}$ enzymes to the formation of the hydroxypyrimidine metabolite of PF-5190457.

$\mathrm{AO}$ and $\mathrm{XO}$ enzymes belong to a family of molybdo-flavoenzymes and have a high level of similarity between their amino acid sequences (Beedham, 1987; Terao et al., 2000; Hille, 2005). The physiologic relevance of $\mathrm{AO}$ is still not known, but $\mathrm{XO}$ plays an important role in catalyzing hypoxanthine to xanthine and later to uric acid (Beedham, 1985; Kitamura et al., 2006). Generally, these enzymes differ in substrate and inhibitor specificity. An increasing number of compounds in the past few decades have been identified to be substrates of these enzymes, especially involving AO, which also has broader substrate specificity in comparison with XO (O'Connor et al., 2006; Pryde et al., 2010; Sanoh et al., 2015; Battelli et al., 2016). There are only a few substrates that show biotransformation by both enzymes, such as 6-deoxyclovir, 6-thioxanthine, and recently VU0409106, a lead compound for 
Raloxifene

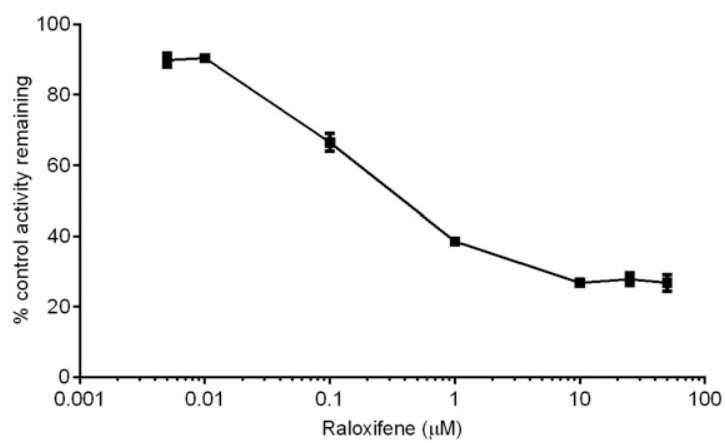

Febuxostat

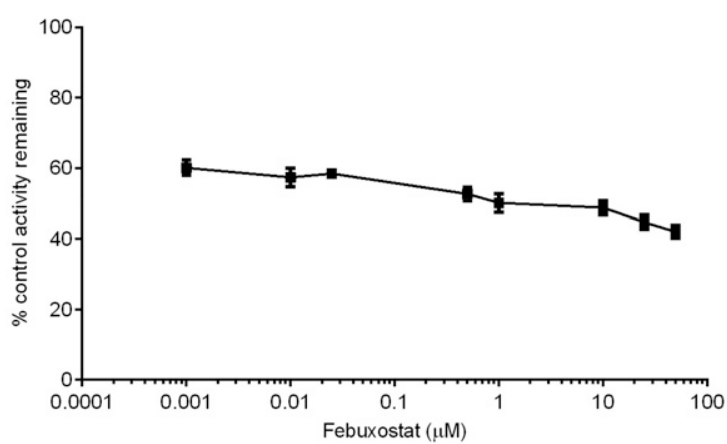

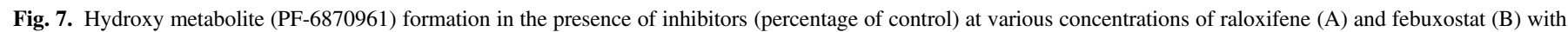
$25 \mu \mathrm{M}$ PF-5190457 in HLC incubations.

childhood developmental disorders (Krenitsky et al., 1984; Morrison et al., 2012; Choughule et al., 2014). Although some overlap exists between the substrates, there have been chemical inhibitors identified specifically for AO and XO including raloxifene (Obach, 2004), hydralazine (Strelevitz et al., 2012), allopurinol (Panoutsopoulos et al., 2004), and febuxostat (Weidert et al., 2014). Allopurinol has been widely used as a known XO inhibitor, but recently it was identified that febuxostat is a more potent inhibitor of XO than allopurinol (Malik et al., 2011). There are no important clinical drug-drug interactions associated with inhibition of $\mathrm{AO}$, but as growth in new chemical entities metabolized by AO is increasing, there could arise a need to characterize the drug-drug interaction potential at the AO level (Obach, 2004; Pryde et al., 2010). Allopurinol, an XO inhibitor, significantly inhibited 6-mercaptopurine (an XO substrate) when administered orally and there was a significant increase in peak plasma concentration and area under the curve of 6-mercaptopurine in patients with acute lymphoblastic leukemia (Zimm et al., 1983). Both potent XO inhibitors, allopurinol and febuxostat, are clinically used for the treatment of chronic gout and hyperuricemia. This condition is also present in disease states such as metabolic syndrome, diabetes, chronic liver disease, and cardiovascular disease (Hu and Tomlinson, 2008; George and Minter, 2017). It is a challenge to capture the drug interactions associated with these enzymes in animal models, especially for AO due to significant species, gender, and strain-specific differences in its expression and activity (Itoh, 2009; Crouch et al., 2017; Mao et al., 2018).

The findings from this study suggest that both $\mathrm{AO}$ and $\mathrm{XO}$ contribute to the metabolism of PF-5190457, resulting in the formation of PF-6870961. In cytosol, raloxifene and febuxostat (inhibitors of $\mathrm{AO}$ and $\mathrm{XO}$, respectively) yielded estimates of maximum inhibition values of slightly in excess of $75 \%$ and $50 \%$, respectively. These sums to over $100 \%$ and may suggest some overlap of the inhibitor selectivity; a not uncommon phenomenon for inhibitors used in reaction phenotyping studies. The study also emphasizes the importance of these noncytochrome P450 enzymes in drug metabolism during the early stages of drug development. Preliminary in vitro work on the metabolism of this compound predated findings that emerged in the literature on the potential importance of molybdenum cofactor enzymes (e.g., Magee et al., 2009; Dalvie et al., 2010; Pryde et al., 2010) and focused on the oxidative component catalyzed by cytochrome P450 enzymes. Thus, it was in human plasma samples where the first observation was made on the predominance of this metabolite ultimately found to be generated by AO and XO. The understanding of this clearance pathway for PF-5190457 will be important in its continued investigation as a therapeutic agent, especially in subjects with alcohol use disorder.

In summary, this study provides important novel information from different points of view: 1) it provides additional new information on the recently developed novel compound PF-5190457, the first growth hormone secretagogue receptor 1a blocker that has moved to development in humans; 2) it provides an example of a reverse translational approach where a discovery in humans was brought back, validated, and further investigated at the bench level; and 3) it demonstrates the importance of considering the molybdenum-containing oxidases during the development of new drug entities.

\section{Acknowledgments}

The authors thank the research staff in the Clinical Pharmacokinetics Research Laboratory at the University of Rhode Island. The authors also thank the clinical and research staff involved in data collection and support at the National Institute on Alcohol Abuse and Alcoholism (NIAAA) Division of Intramural Clinical and Biological Research, i.e., in the NIAAA/National Institute on Drug Abuse Section on Clinical Psychoneuroendocrinology and Neuropsychopharmacology and the NIAAA clinical intramural program. The authors also thank the clinical and research staff involved in data collection and patient care at the National Institutes of Health Clinical Center, i.e. in the Department of Nursing (in particular, the nurses of the 1SE Inpatient Unit and of the 1-HALC 1SE Outpatient Clinic), Department of Nutrition, and Department of Pharmacy. Furthermore, the authors express their gratitude to the participants who took part in the phase $1 \mathrm{~b}$ clinical study. Finally, the authors thank the Steering Committee, whose members included members from the NIAAA Division of Medication Development (in particular, Dr. Joanne Fertig), the Drug Development Partnership Programs of the National Center for Advancing Translational Sciences (NCATS), and Pfizer, which kindly provided the study drug for the phase $1 \mathrm{~b}$ clinical study under the NCATS grant.

\section{Authorship Contributions}

Participated in research design: Obach, Leggio, Akhlaghi.

Conducted experiments: Adusumalli, Jamwal, Obach, Ryder.

Contributed new reagents or analytic tools: Obach, Leggio, Akhlaghi.

Performed data analysis: Adusumalli, Jamwal, Obach, Ryder, Leggio, Akhlaghi.

Wrote or contributed to the writing of the manuscript: Adusumalli, Jamwal, Obach, Ryder, Leggio, Akhlaghi.

\section{References}

Asakawa A, Inui A, Kaga T, Yuzuriha H, Nagata T, Ueno N, Makino S, Fujimiya M, Niijima A Fujino MA, et al. (2001) Ghrelin is an appetite-stimulatory signal from stomach with structural resemblance to motilin. Gastroenterology 120:337-345.

Battelli MG, Polito L, Bortolotti M, and Bolognesi A (2016) Xanthine oxidoreductase in drug metabolism: beyond a role as a detoxifying enzyme. Curr Med Chem 23: $4027-4036$.

Beedham C (1985) Molybdenum hydroxylases as drug-metabolizing enzymes. Drug Metab Rev 16:119-156.

Beedham C (1987) Molybdenum hydroxylases: biological distribution and substrate-inhibitor specificity. Prog Med Chem 24:85-127.

Bhattacharya SK, Andrews K, Beveridge R, Cameron KO, Chen C, Dunn M, Fernando D, Gao H, Hepworth D, Jackson VM, et al. (2014) Discovery of PF-5190457, a potent, selective, and orally bioavailable ghrelin receptor inverse agonist clinical candidate. ACS Med Chem Lett 5:474-479. 
Choughule KV, Barnaba C, Joswig-Jones CA, and Jones JP (2014) In vitro oxidative metabolism of 6-mercaptopurine in human liver: insights into the role of the molybdoflavoenzymes aldehyde oxidase, xanthine oxidase, and xanthine dehydrogenase. Drug Metab Dispos 42:1334-1340.

Crouch RD, Blobaum AL, Felts AS, Conn PJ, and Lindsley CW (2017) Species-specific involvement of aldehyde oxidase and xanthine oxidase in the metabolism of the pyrimidinecontaining mGlu $_{5}$-negative allosteric modulator VU0424238 (auglurant). Drug Metab Dispos 45:1245-1259.

Dalvie D, Zhang C, Chen W, Smolarek T, Obach RS, and Loi CM (2010) Cross-species comparison of the metabolism and excretion of zoniporide: contribution of aldehyde oxidase to interspecies differences. Drug Metab Dispos 38:641-654.

Damian M, Marie J, Leyris JP, Fehrentz JA, Verdié P, Martinez J, Banères JL, and Mary S (2012) High constitutive activity is an intrinsic feature of ghrelin receptor protein: a study with a functional monomeric GHS-R1a receptor reconstituted in lipid discs. J Biol Chem 287: 3630-3641.

Denney WS, Sonnenberg GE, Carvajal-Gonzalez S, Tuthill T, and Jackson VM (2017) Pharmacokinetics and pharmacodynamics of PF-05190457: the first oral ghrelin receptor inverse agonist to be profiled in healthy subjects. Br J Clin Pharmacol 83:326-338.

Farokhnia M, Grodin EN, Lee MR, Oot EN, Blackburn AN, Stangl BL, Schwandt ML, Farinelli LA, Momenan R, Ramchandani VA, et al. (2018) Exogenous ghrelin administration increase alcohol self-administration and modulates brain functional activity in heavy-drinking alcoholdependent individuals. Mol Psychiatry 23:2029-2038.

Fu C, Di L, Han X, Soderstrom C, Snyder M, Troutman MD, Obach RS, and Zhang H (2013) Aldehyde oxidase 1 (AOX1) in human liver cytosols: quantitative characterization of AOX1 expression level and activity relationship. Drug Metab Dispos 41:1797-1804.

George C and Minter DA (2017) Hyperuricemia, StatPearls, Treasure Island, FL.

Hille R (2005) Molybdenum-containing hydroxylases. Arch Biochem Biophys 433:107-116.

Howard AD, Feighner SD, Cully DF, Arena JP, Liberator PA, Rosenblum CI, Hamelin M, Hreniuk DL, Palyha OC, Anderson J, et al. (1996) A receptor in pituitary and hypothalamus that function in growth hormone release. Science 273:974-977.

Hu M and Tomlinson B (2008) Febuxostat in the management of hyperuricemia and chronic gout: a review. Ther Clin Risk Manag 4:1209-1220.

Inui A, Asakawa A, Bowers CY, Mantovani G, Laviano A, Meguid MM, and Fujimiya M (2004) Ghrelin, appetite, and gastric motility: the emerging role of the stomach as an endocrine organ. FASEB $J$ 18:439-456.

Itoh K (2009) [Individual and strain differences of aldehyde oxidase in the rat]. Yakugaku Zasshi 129:1487-1493.

Jamwal R, Barlock BJ, Adusumalli S, Ogasawara K, Simons BL, and Akhlaghi F (2017) Multiplex and label-free relative quantification approach for studying protein abundance of drug metabolizing enzymes in human liver microsomes using SWATH-MS J Proteome Res 16:4134-4143.

Kitamura S, Sugihara K, and Ohta S (2006) Drug-metabolizing ability of molybdenum hydroxylases. Drug Metab Pharmacokinet 21:83-98.

Kojima M, Hosoda H, Date Y, Nakazato M, Matsuo H, and Kangawa K (1999) Ghrelin is a growth-hormone-releasing acylated peptide from stomach. Nature 402:656-660.

Krenitsky TA, Hall WW, de Miranda P, Beauchamp LM, Schaeffer HJ, and Whiteman PD (1984) 6-Deoxyacyclovir: a xanthine oxidase-activated prodrug of acyclovir. Proc Natl Acad Sci USA 81:3209-3213.

Krenitsky TA, Neil SM, Elion GB, and Hitchings GH (1972) A comparison of the specificities of xanthine oxidase and aldehyde oxidase. Arch Biochem Biophys 150:585-599.

Kumar GN and Surapaneni S (2001) Role of drug metabolism in drug discovery and development Med Res Rev 21:397-411.

Lee MR, Tapocik JD, Ghareeb M, Schwandt ML, Dias AA, Le AN, Cobbina E, Farinelli LA, Bouhlal S, Farokhnia M, et al. (2018) The novel ghrelin receptor inverse agonist PF-5190457 administered with alcohol: preclinical safety experiments and a phase $1 \mathrm{~b}$ human laboratory study. Mol Psychiatry DOI: 10.1038/s41380-018-0064-y [published ahead of print].

Leggio L (2010) Role of the ghrelin system in alcoholism: acting on the growth hormone secretagogue receptor to treat alcohol-related diseases. Drug News Perspect 23:157-166.

Leggio L, Addolorato G, Cippitelli A, Jerlhag E, Kampov-Polevoy AB, and Swift RM (2011) Role of feeding-related pathways in alcohol dependence: a focus on sweet preference, NPY, and ghrelin. Alcohol Clin Exp Res 35:194-202.

Leggio L, Zywiak WH, Fricchione SR, Edwards SM, de la Monte SM, Swift RM, and Kenna GA (2014) Intravenous ghrelin administration increases alcohol craving in alcohol-dependent heavy drinkers: a preliminary investigation. Biol Psychiatry 76:734-741.

Lin JH and Lu AY (1997) Role of pharmacokinetics and metabolism in drug discovery and development. Pharmacol Rev 49:403-449.

Magee TV, Ripp SL, Li B, Buzon RA, Chupak L, Dougherty TJ, Finegan SM, Girard D, Hagen AE, Falcone MJ, et al. (2009) Discovery of azetidinyl ketolides for the treatment of susceptible and multidrug resistant community-acquired respiratory tract infections. J Med Chem 52: 7446-7457.

Malik UZ, Hundley NJ, Romero G, Radi R, Freeman BA, Tarpey MM, and Kelley EE (2011) Febuxostat inhibition of endothelial-bound XO: implications for targeting vascular ROS production. Free Radic Biol Med 51:179-184.

Mao Z, Wu Y, Li Q, Wang X, Liu Y, and Di X (2018) Aldehyde oxidase-dependent species difference in hepatic metabolism of fasudil to hydroxyfasudil. Xenobiotica 48:170-177.

Morris LS, Voon V, and Leggio L (2018) Stress, motivation, and the gut-brain axis: a focus on the ghrelin system and alcohol use disorder. Alcohol Clin Exp Res 42:1387-1389 DOI: 10.1111/ acer.13781.

Morrison RD, Blobaum AL, Byers FW, Santomango TS, Bridges TM, Stec D, Brewer KA, Sanchez-Ponce R, Corlew MM, Rush R, et al. (2012) The role of aldehyde oxidase and xanthine oxidase in the biotransformation of a novel negative allosteric modulator of metabotropic glutamate receptor subtype 5. Drug Metab Dispos 40:1834-1845.

Nagaya N, Itoh T, Murakami S, Oya H, Uematsu M, Miyatake K, and Kangawa K (2005) Treatment of cachexia with ghrelin in patients with COPD. Chest 128:1187-1193.

Nagaya N, Moriya J, Yasumura Y, Uematsu M, Ono F, Shimizu W, Ueno K, Kitakaze M, Miyatake K, and Kangawa K (2004) Effects of ghrelin administration on left ventricular function, exercise capacity, and muscle wasting in patients with chronic heart failure. Circulation 110:3674-3679.

Neary NM, Small CJ, Wren AM, Lee JL, Druce MR, Palmieri C, Frost GS, Ghatei MA, Coombes RC, and Bloom SR (2004) Ghrelin increases energy intake in cancer patients with impaired appetite: acute, randomized, placebo-controlled trial. J Clin Endocrinol Metab 89:2832-2836.

Obach RS (2004) Potent inhibition of human liver aldehyde oxidase by raloxifene. Drug Metab Dispos 32:89-97.

O'Connor D, Jones P, Chambers MS, Maxey R, Szekeres HJ, Szeto N, Scott-Stevens P, Macleod AM, Braun M, and Cato B (2006) Aldehyde oxidase and its contribution to the metabolism of a structurally novel, functionally selective $\mathrm{GABA}_{\mathrm{A}} \alpha 5$-subtype inverse agonist. Xenobiotica 36 $315-330$.

Ortiz de Montellano PR and Mathews JM (1981) Autocatalytic alkylation of the cytochrome P-450 prosthetic haem group by 1-aminobenzotriazole. Isolation of an NN-bridged benzyne-protoporphyrin IX adduct. Biochem $J$ 195:761-764.

Panoutsopoulos GI, Kouretas D, and Beedham C (2004) Contribution of aldehyde oxidase, xanthine oxidase, and aldehyde dehydrogenase on the oxidation of aromatic aldehydes. Chem Res Toxicol 17:1368-1376.

Pryde DC, Dalvie D, Hu Q, Jones P, Obach RS, and Tran TD (2010) Aldehyde oxidase: an enzyme of emerging importance in drug discovery. $J$ Med Chem 53:8441-8460.

Sanoh S, Tayama Y, Sugihara K, Kitamura S, and Ohta S (2015) Significance of aldehyde oxidase during drug development: effects on drug metabolism, pharmacokinetics, toxicity, and efficacy. Drug Metab Pharmacokinet 30:52-63.

Strelevitz TJ, Orozco CC, and Obach RS (2012) Hydralazine as a selective probe inactivator of aldehyde oxidase in human hepatocytes: estimation of the contribution of aldehyde oxidase to metabolic clearance. Drug Metab Dispos 40:1441-1448.

Terao M, Kurosaki M, Saltini G, Demontis S, Marini M, Salmona M, and Garattini E (2000) Cloning of the cDNAs coding for two novel molybdo-flavoproteins showing high similarity with aldehyde oxidase and xanthine oxidoreductase. J Biol Chem 275:30690-30700.

Tong J, Prigeon RL, Davis HW, Bidlingmaier M, Kahn SE, Cummings DE, Tschöp MH, and D'Alessio D (2010) Ghrelin suppresses glucose-stimulated insulin secretion and deteriorates glucose tolerance in healthy humans. Diabetes 59:2145-2151.

Volkow ND, Wang GJ, Tomasi D, and Baler RD (2013) Obesity and addiction: neurobiologica overlaps. Obes Rev 14:2-18.

Weidert ER, Schoenborn SO, Cantu-Medellin N, Choughule KV, Jones JP, and Kelley EE (2014) Inhibition of xanthine oxidase by the aldehyde oxidase inhibitor raloxifene: implications for identifying molybdopterin nitrite reductases. Nitric Oxide 37:41-45.

Zallar LJ, Farokhnia M, Tunstall BJ, Vendruscolo LF, and Leggio L (2017) The role of the ghrelin system in drug addiction. Int Rev Neurobiol 136:89-119.

Zimm S, Collins JM, O'Neill D, Chabner BA, and Poplack DG (1983) Inhibition of first-pass metabolism in cancer chemotherapy: interaction of 6-mercaptopurine and allopurinol. Clin Pharmacol Ther 34:810-817.

Address correspondence to: Fatemeh Akhlaghi, Clinical Pharmacokinetics Research Laboratory, Department of Biomedical and Pharmaceutical Sciences, Avedisian Hall, 7 Greenhouse Road, University of Rhode Island, Kingston, RI. E-mail: fatemeh@uri.edu 